\begin{tabular}{|l|l|}
$\begin{array}{l}\text { Postprint } \\
\text { Version }\end{array}$ & 1.0 \\
\hline Journal website & http://www.sciencedirect.com/science/article/pii/S0306460314003372 \\
\hline Pubmed link & http://www.ncbi.nlm.nih.gov/pubmed/?term=25453782 \\
\hline DOI & $10.1016 /$ j.addbeh.2014.10.005
\end{tabular}

This is a NIVEL certified Post Print, more info at http://www.nivel.eu

\title{
Less than meets the eye: Reappraising the clinical relevance of attentional bias in addiction
}

\author{
Paul Christiansen $^{\mathrm{A}, \mathrm{B},}$, , Tim M. SchoenmaKers ${ }^{\mathrm{C}, \mathrm{D}}$, MATt Field $^{\mathrm{A}, \mathrm{B}}$ \\ ${ }^{\text {a }}$ Department of Psychological Sciences, University of Liverpool, Liverpool, United Kingdom \\ ${ }^{\mathrm{b}}$ UK Centre for Tobacco and Alcohol Studies (UKCTAS), United Kingdom \\ ${ }^{c}$ IVO Addiction Research Institute, Rotterdam, The Netherlands \\ ${ }^{\mathrm{d}}$ Erasmus Medical Center, Rotterdam, The Netherlands
}

\begin{abstract}
Recent years have seen an explosion of interest in attentional bias in addiction, particularly its clinical relevance. Specifically, numerous articles claimed to demonstrate either that (1) attentional bias measured in treatment settings could predict subsequent relapse to substance use, or (2) direct modification of attentional bias reduced substance use and improved treatment outcomes. In this paper, we critically evaluate empirical studies that investigated these issues. We show that the evidence regarding both of these claims is decidedly mixed, and that many of the studies that appear to yield positive findings have serious methodological and statistical limitations. We contend that the available literature suggests that attentional bias for drug cues fluctuates within individuals because it is an output of the underlying motivational state at that moment in time, but there is no convincing evidence that it exerts a causal influence on substance use. Future research should make use of experience sampling methodology to characterise the clinical significance of fluctuations in attentional bias over time.
\end{abstract}

\section{Introduction}

Motivationally-relevant cues attract and hold the attention: the hungry dieter will notice cakes in the canteen, the anxious person will detect threatening shapes in the shadows, and the depressed person will focus on the negative comments amongst the positive. Attentional bias (AB) towards substance-related cues is also seen in people who frequently use those substances, including individuals with substance use disorders (American Psychiatric Association, 2013). Literature documenting the 
Christiansen, P., Schoenmakers, T.M., Field, M. Less than meets the eye: reappraising the

presence of $\mathrm{AB}$ in substance users has been extensively reviewed elsewhere (Cox et al., 2006, Field and Cox, 2008 and Wiers et al., 2014) and this evidence is consistent with theoretical models which posit that $\mathrm{AB}$ plays a causal role in the onset, maintenance and recurrence (relapse) of substance use disorders after a period of abstinence (Cox et al., 2006, Franken, 2003, Field and Cox, 2008 and Wiers et al., 2014).

Three recent narrative reviews (Cox et al., 2014, Field et al., 2014 and Marhe et al., 2014) reviewed the clinical relevance of $A B$ in substance use disorders and reached quite different conclusions despite considering many of the same studies. In the current review we offer a comprehensive, detailed, and critical review of studies that investigated two key issues: the predictive validity of $\mathrm{AB}$ as a predictor of relapse to substance use after treatment, and the efficacy of attentional bias modification $(\mathrm{ABM})$ as an intervention to prevent relapse or reduce substance use among those with substance use disorders. In contrast to the other recent reviews, which aimed to provide a broad overview of the literature, our goal here is to critically dissect the methods used and results that were reported in previous studies. Our conclusions are considerably more pessimistic than those offered in other reviews, and by the authors of much of the original research. The important theoretical and clinical implications of our review will be highlighted throughout this paper.

\section{MEASUREMENT ISSUES AND LITERATURE SEARCH STRATEGY}

Although a number of measures of $\mathrm{AB}$ for substance cues have been described, the addiction Stroop task and the visual probe task are the most frequently used and to our knowledge these are the only two measures that have been used to investigate the issues that are central to this review paper. Full descriptions of both measures and discussions of their strengths, weaknesses and underlying psychological processes can be found elsewhere (Field and Cox, 2008 and Field, Duka, Tyler and Schoenmakers, 2009). Importantly, both tasks rely on measurements of manual reaction time to make inferences about attentional deployment.

In the addiction Stroop task, participants are instructed to name the colour in which substance-related and matched neutral words are printed, whilst ignoring the content of those words. Slower colour-naming times for substance-related words are interpreted to indicate that those words captured the attention (Cox et al., 2006), but it should be noted that slower colour naming could also reflect a non-specific freezing response to stimuli that are perceived as threatening (Algom et al., 2004 and Greenaway et al., 2012), cognitive avoidance of stimuli that are perceived as threatening (De Ruiter \& Brosschot, 1994), or individual differences in general inhibitory control ability (Crunelle, Veltman, Booij, van Emmerik-van Oortmerssen, $\&$ van den Brink, 2012).

In the visual probe task, a pair of words or images is presented side-by-side on a computer screen before being removed and replaced by a visual probe that appears on one side of the screen. Participants must respond to this probe as quickly as possible and $\mathrm{AB}$ is inferred if they are faster to respond to probes that replace substance-related words or images compared to probes that replace neutral images. Both of these tasks are characterised by unacceptably low internal reliability, particularly the visual probe task for which internal reliability may be close to zero (Ataya et al., 2012). Although there is debate about the reliability of both measuresit is undoubtedly poor, but may not be bad as Ataya et al. have suggested based on a 
Christiansen, P., Schoenmakers, T.M., Field, M. Less than meets the eye: reappraising the clinical relevance of attentional bias in addiction. Addictive Behaviors: 2015, 44(44-50), 44-50

re-analysis of only their own data (see Field \& Christiansen, 2012) — this issue is important for understanding the predictive validity of the tasks, and we return to it later in the paper.

This review is concerned with relapse, specifically the relationship between $A B$ and relapse to substance use after a period of abstinence, and the effects of ABM on relapse in patients who are trying to abstain. Different researchers have used different definitions and indicators of relapse, and there is no universally accepted 'gold standard' measure. One could argue that it should be treated as a dichotomous variable (within a pre-defined follow-up period), but given that it is normal for patients to have multiple relapses before they eventually achieve abstinence, this measure may not adequately capture the nature of recovery from substance use disorders. Alternative measures, such as the duration of abstinence/latency to relapse have been reported in some studies and arguably this is more appropriate from both a clinical perspective (because it yields a more detailed description of progress) and a methodological one, because it has greater statistical power. Another important point is that some patients have a goal of reducing their substance use rather than abstaining altogether, in which case indices of the quantity or frequency of substance use may be more informative than crudely categorising participants as relapsed or abstinent.

In this review, we included peer-reviewed studies that have been published or accepted for publication in peer-reviewed journals. Studies were initially identified on the basis of review articles (Cox et al., 2006, Franken, 2003, Field and Cox, 2008, Wiers et al., 2014, Cox et al., 2014, Field et al., 2014 and Marhe et al., 2014), and based on searches of Scopus and PubMed using the following search terms: 'Attentional bias OR Stroop' AND 'addiction OR alcohol OR tobacco OR nicotine OR smoking OR drug OR cannabis OR marijuana OR cocaine OR heroin OR opiates OR amphetamine'. These searches resulted in 1172 results. The titles and abstracts of these papers were inspected to identify any papers that investigated either (1) the relationship between $\mathrm{AB}$ and subsequent substance use or relapse, or (2) the effects of ABM. A total of 28 articles, describing 27 unique studies, were retained for detailed consideration: 16 papers (15 studies) for the first section (prediction of relapse, Table 1) and 12 papers (12 studies) for the second (ABM). We did not conduct a formal meta-analysis or report effect sizes because the variation in predictor and outcome measures used in different studies would have rendered statistical comparisons between studies meaningless. In any case, our primary aim was to critically discuss the methods used and interpretation of data obtained in previous studies, something that could not have been achieved with meta-analysis.

\section{[TABLE 1]}

\section{PREDICTIVE VALIDITY: DOES ATTENTIONAL BIAS PREDICT RELAPSE?}

The first issue is whether $\mathrm{AB}$ can predict relapse to substance use in people who are currently attempting to maintain abstinence. If so, the implication would be that $\mathrm{AB}$ is a valid indicator of presumably stable individual differences in the psychological processes that underlie loss of control over substance use, as opposed to an unwelcome but ultimately irrelevant consequence of chronic substance use ( Field and Cox, 2008, Franken, 2003 and Wiers et al., 2014). This would also be consistent with claims that $\mathrm{AB}$ could causally influence substance consumption, although the 
Christiansen, P., Schoenmakers, T.M., Field, M. Less than meets the eye: reappraising the

only true test of AB's causal role can come from studies of ABM, which we discuss in the next section. If the predictive validity of $\mathrm{AB}$ measured in clinical settings could be established this would also have immediate clinical applications, because it could be used to assess a patient's prognosis and their need for more intensive relapse prevention interventions.

Several studies reported that performance on the addiction Stroop (measured in the clinic) predicted subsequent relapse in those attempting abstinence (Carpenter et al., 2006, Cox et al., 2002, Janes et al., 2010, Marissen et al., 2006, Powell et al., 2010 and Waters, Shiffman, Sayette, et al., 2003) and one additional study reported that performance on the alcohol Stroop predicted reduction in drinking among problem drinkers who did not have an abstinence goal (Cox, Pothos, \& Hosier, 2007). However, three other studies used the Stroop and failed to find this relationship (Field et al., 2013, Kennedy et al., 2014 and Marhe, Luijten, Van De Wetering, Smits and Franken, 2013), and three additional studies found a relationship between Stroop interference and treatment outcome, but in the opposite direction (i.e. larger attentional bias was associated with better treatment outcomes; Carpenter et al., 2012, Mitchell et al., 2013 and Spiegelhalder et al., 2011). Three of the aforementioned studies also included a visual probe task, and all found no significant relationship between this measure of attentional bias and subsequent relapse (Field et al., 2013, Spiegelhalder et al., 2011 and Waters, Shiffman, Bradley and Mogg, 2003). The latter refers to the same study as the earlier paper by Waters, Shiffman, Sayette, et al. (2003), but the Stroop and visual probe task data were reported in two different articles. Significantly, only one paper to date has reported an association between attentional bias measured by the visual probe task and relapse (Garland, Franken, \& Howard, 2012).

A simple comparison of 'hits' and 'misses' suggests that the evidence is equivocal: Seven hits to six misses for the addiction Stroop, and one hit to three misses for the visual probe task. Most of these studies (including those that reported positive findings) were probably underpowered to detect any relationship between attentional bias and treatment outcome, and it is notable that underpowered studies can yield spurious positive as well as null findings (Button et al., 2013). More importantly, we contend that methodological weaknesses and inconsistencies mean that many of the apparently positive findings cannot be taken at face value.

For example, Carpenter et al. (2006) reported that Stroop interference for cocaine words predicted treatment outcome in cocaine-dependent patients. However in this study, the authors tested three groups of participants (those with primary cocaine, cannabis or heroin dependence), measured Stroop interference for four different types of words (cannabis, heroin, cocaine, and mixed drug), and they recorded eight different measures of treatment outcome: two or three for each different group. They then correlated all of the Stroop interference scores (four) with all of the treatment outcome measures (eight). Crucially, the authors did not correct for multiple statistical comparisons (total $=32$ ), and therefore the total number of significant correlations that were reported (six) should be interpreted with caution. Indeed, authors reported that cocaine attentional bias was significantly correlated with one measure of treatment outcome in the cannabis group, heroin attentional bias was correlated with a different measure of treatment outcome in the cannabis group, but cannabis attentional bias was unrelated to outcomes in this group. This raises concerns that it was not a drug-specific attentional bias that was associated with 
Christiansen, P., Schoenmakers, T.M., Field, M. Less than meets the eye: reappraising the clinical relevance of attentional bias in addiction. Addictive Behaviors: 2015, 44(44-50), 44-50

relapse. Instead, individuals who were more distracted by drug-related words in general were more likely to relapse, and this might reflect the broader effects of inhibitory control rather than attentional bias per se (see Streeter et al., 2008). In another early study (Cox et al., 2002), Stroop interference for alcohol-related words was measured in a sample of alcohol-dependent patients $(N=14)$ on admission for treatment and again at the end of treatment, four weeks later. A control group $(N=16)$ were also tested twice, four weeks apart. The primary finding reported by Cox et al. (2002) was that in the patients who relapsed after treatment $(N=9)$, attentional bias increased from pre- to post-treatment. By contrast, in patients who remained abstinent $(N=5)$, attentional bias appeared to decline slightly over the course of treatment, which is consistent with other studies of patients who were able to maintain abstinence ( Flaudias et al., 2013 and Gardini et al., 2009). Importantly, in the Cox et al. (2002) study, it appears that Stroop interference at the beginning of the study (on admission to treatment) was lower in the (eventual) relapsers compared to the abstainers, although it is not clear if this difference was statistically significant (the contrast was not reported in the paper). Nonetheless, it seems likely that regression to the mean is a plausible explanation for the increase in attentional bias over time in the group who subsequently relapsed, an explanation that was not considered by the authors.

Even though the addiction Stroop is a simple task, researchers have analysed a variety of outcome measures from it. For example, Waters, Shiffman, Sayette, et al. (2003) focussed their analyses on the 'acute Stroop' (the first few trials of the task) and reported that this measure predicted relapse to smoking, but analyses that included all trials of the task were only marginally significant predictors of relapse. Powell et al., 2010's conclusions about the predictive validity of the Stroop were based on an analysis of error rates rather than reaction times, and they did not report an analysis of the reaction time data. Two other smoking Stroop studies reported that the overall reaction time index of attentional bias, but not overall errors, were predictive of subsequent relapse (Janes et al., 2010 and Waters, Shiffman, Sayette, et al., 2003). We highlight these three studies because a cursory glance suggests that all three demonstrate the same finding, whereas closer inspection reveals that the findings are not consistent with each other at all.

Overall, it seems that the relationship between attentional bias measured in the clinic and subsequent relapse is inconsistent across studies. However, a recent study employed ecological momentary assessment (EMA) methods to investigate a slightly different question: does attentional bias increase immediately before patients relapse? Marhe, Waters, Van De Wetering, and Franken (2013) administered their drug Stroop task on a handheld computer. Patients who were receiving inpatient treatment for heroin dependence completed the Stroop task whenever they felt tempted to use heroin ('temptation assessments'), and whenever they received a random prompt. The authors reported that attentional bias during the 'temptation assessments' was significantly higher among patients who relapsed compared to those who maintained abstinence. Most importantly, attentional bias peaked just before relapse occurred. We suggest that attempts to replicate this study should be a high priority for researchers, because if these findings can be replicated it would suggest that attentional bias does predict relapse, but only just before the relapse occurs. However, the other studies reviewed in this section suggest that the predictive 
Christiansen, P., Schoenmakers, T.M., Field, M. Less than meets the eye: reappraising the

validity of attentional bias measured in a clinical setting weeks, days or even months before relapse eventually occurs is unclear.

\section{THE CAUSAL ROLE OF ATTENTIONAL BIAS: ATTENTIONAL BIAS MODIFICATION} Arguably the most straightforward way to demonstrate that variable $X$ has a causal influence on variable $Y$ is to experimentally manipulate $X$ in order to observe the effect on $Y$ ( Hill, 1965). Attentional bias modification (ABM) is an experimental procedure that can be adapted to produce either increases or decreases in attentional bias. It has been applied to investigate the causal influence of attentional bias for a range of disorder-related stimuli on subjective states and behaviour. For example, ABM that reduces attentional bias for threatening stimuli leads to small but robust reductions in subjective anxiety, particularly after exposure to a stressor ( Beard et al., 2012 and Mogoaşe et al., 2014). There is convincing evidence that AB has a causal influence in anxiety disorders, although the magnitude and clinical significance of this effect are hotly debated ( Clarke et al., 2014 and Emmelkamp, 2012).

The published addiction ABM studies are summarised in Table 2. Six laboratorybased studies employed a single session of ABM using a modified visual probe task in which the location of probes was systematically varied so that participants would be encouraged either to look toward substance cues ('Attend' groups, increased attentional bias), or away from those cues ('Avoid' groups, reduced attentional bias). Some of these studies included a control group of participants who completed a standard visual probe task. Shortly after the end of the ABM procedure, participants completed self-report measures of drug craving and/or behavioural measures of substance self-administration or the motivation to obtain the substance.

\section{[TABLE 2]}

Firstly, Field and Eastwood (2005) allocated heavy social drinkers to 'Attend' or 'Avoid' groups who were trained to direct their attention toward or away from alcohol-related pictures, respectively. In this study, ABM led to the predicted group differences in $\mathrm{AB}$ immediately after training, and these changes in attentional bias were accompanied by elevated subjective alcohol craving (albeit in only one of two measures of craving that were administered) and increased beer consumption, in the Attend group compared to the Avoid group. Therefore, these results were interpreted as demonstrating that attentional bias for alcohol cues had a causal influence on alcohol craving and consumption.

Results from subsequent studies were less promising. Field et al. (2007) replicated and extended the earlier study by contrasting Attend, Avoid and Control groups and incorporating novel alcohol-related pictures (that had not been used during ABM) and different measures of $\mathrm{AB}$ into the pre- and post- $\mathrm{ABM}$ assessments. As predicted, $\mathrm{ABM}$ led to increased $\mathrm{AB}$ in the Attend group, decreased $\mathrm{AB}$ in the Avoid group, and no change in the Control group. Unexpectedly, both the Attend and Avoid groups showed increased attentional bias for novel alcohol pictures after ABM (compared to before ABM), but there was no generalisation to different measures of AB. Most importantly, the group differences in beer consumption reported in the earlier study ( Field \& Eastwood, 2005), were not replicated, and the increase in subjective craving after ABM in the Attend group was only seen in a subgroup of participants (those aware of the task contingencies during ABM). A study published 
Christiansen, P., Schoenmakers, T.M., Field, M. Less than meets the eye: reappraising the clinical relevance of attentional bias in addiction. Addictive Behaviors: 2015, 44(44-50), 44-50

in the same year (Schoenmakers, Wiers, Jones, Bruce, \& Jansen, 2007) compared Avoid and Control conditions and reported comparable findings: Reduced AB in the Avoid group after training, which did not generalise to novel stimuli or a different $\mathrm{AB}$ task, and which did not produce a change in alcohol craving or drinking behaviour. Pessimistically, one might say that the ABM intervention in these studies did not really lead to a change in $\mathrm{AB}$, because effects were only found on the task on which participants were trained, and they did not generalise to novel stimuli or different AB tasks.

Three studies investigated the effects of a single session of ABM in tobacco smokers and all failed to observe an effect on smoking behaviour. Firstly, Attwood, O'Sullivan, Leonards, Mackintosh, and Munafò, (2008) contrasted Attend and Avoid groups and demonstrated the predicted group differences in $\mathrm{AB}$ after ABM, but no effect on smoking behaviour. Craving increased over the course of ABM in both groups although the magnitude of the increase was slightly larger in the Attend group, albeit in male participants only (and was also limited to participants who were aware of ABM contingencies, as in Field et al., 2007). Field, Duka, Tyler, and Schoenmakers (2009) compared Attend, Avoid and Control groups and although they demonstrated the predicted group differences in $\mathrm{AB}$ following $\mathrm{ABM}$, there was no evidence of generalisation to novel stimuli or AB tasks, and there were no effects on craving or smoking behaviour. Finally, McHugh, Murray, Hearon, Calkins, and Otto (2010) compared Avoid and Control groups and demonstrated no group difference in $\mathrm{AB}$ following $\mathrm{ABM}$, and no group difference in subjective craving (smoking behaviour was not measured in this study).

Results from these studies are important because, with one exception (McHugh et al., 2010), they demonstrated that a single session of ABM led to transient changes (increases or decreases) in $\mathrm{AB}$, at least for pictorial stimuli that were used during $\mathrm{ABM}$ and on the $\mathrm{AB}$ task that was used to administer the ABM. However, these alterations in $\mathrm{AB}$ were not consistently associated with increases or decreases in substance craving or behavioural measures of substance-seeking or selfadministration. These results suggest that $\mathrm{AB}$ does not have a causal influence on craving or substance use (see Clarke et al., 2014) and therefore they are problematic for theoretical models which posit this causal influence (Field and Cox, 2008 and Franken, 2003). There was, however, weak evidence for an effect of Attend manipulations (experimentally increasing the attentional bias) on subjective craving, which were reported in three of the six studies, although only in subgroups of participants (Attwood et al., 2008, Field and Eastwood, 2005 and Field et al., 2007). Importantly, in each of these studies, Avoid manipulations did not lead to a parallel decrease in subjective craving. We suggest that this is because Attend manipulations increase participants' exposure to substance cues, which prompts an increase in rumination on substance use, in accordance with theoretical models of $\mathrm{AB}$ (Field and Cox, 2008 and Franken, 2003) and the 'elaborated intrusion' theory of desire (Kavanagh, Andrade, \& May, 2005). However, this relationship between AB and rumination is unfortunately not symmetrical, because Avoid manipulations do not prompt a reduction in rumination and therefore do not lead to a decrease in craving. One statistical limitation with these studies is that researchers have not tested whether $\mathrm{ABM}$ has an indirect effect on behaviour via changes in $\mathrm{AB}$, which is possible even in the absence of a direct effect of $A B M$ on behaviour (see Krause et al., 2010). However, we conducted these analyses on datasets from three single- 
Christiansen, P., Schoenmakers, T.M., Field, M. Less than meets the eye: reappraising the

session ABM studies conducted in our laboratory (Field et al., 2007, Field, Duka, Tyler and Schoenmakers, 2009 and Field and Eastwood, 2005) and did not observe any statistically significant indirect effects (details available on request).

Nonetheless, this is an important issue for future research on this topic and we encourage researchers to explore possible indirect effects of ABM, and also be aware of appropriate analyses that do not rely upon direct effects to ascertain the statistical significance of indirect effects.

Although theoretically informative, single-session ABM studies do not speak to the potential clinical applications of ABM. No Cognitive Behaviour Therapy (CBT) therapist would expect their clients to permanently abstain from substance use after a single session of CBT, because it takes time to learn and practice the coping skills that are needed for long-term behaviour change (Bowen et al., 2014). The same could be true of ABM: Multiple sessions of ABM might be needed to produce a long-lasting and generalisable reduction in AB. Importantly in this regard, many of the studies discussed above tested the generalisability of ABM and all of them found that the effects of a single session did not alter $A B$ for stimuli that were not trained, and effects of $A B M$ did not generalise to different $A B$ tasks. We interpret these findings as indicative that a single session of $\mathrm{ABM}$ teaches participants how to respond efficiently to specific stimuli within the confines of a specific task, and indeed demonstrations (Attwood et al., 2008 and Field et al., 2007) that effects were moderated by participant awareness of training contingencies is consistent with this view. However, demonstrating an improvement in task performance is not the same as demonstrating a reduction in $\mathrm{AB}$ for a broad class of stimuli (e.g. alcohol-related stimuli, for a related argument, see Owen et al., 2010). It is also noteworthy that participants in each of the single session ABM studies were college students who were not motivated to reduce their alcohol consumption or smoking behaviour. The lack of an effect of ABM on craving or actual substance use is therefore unsurprising, and it is important to examine the effects of ABM in participants who are motivated to reduce their substance use, or abstain altogether.

Details of six studies that investigated multiple sessions of ABM are shown in Table 2. The majority of these used a modified visual probe task as described above, and so these will be discussed first. Schoenmakers et al. (2010) administered five sessions of Avoid ABM training or a control intervention (a different reaction time task, that also involved responding to alcohol pictures), within three weeks, to 43 alcohol-dependent patients who were recruited from three clinics in the Netherlands. Encouragingly, Avoid ABM led to a reduction in AB that generalised to novel stimuli that were not used during ABM. Overall relapse rates were unaffected by ABM: 4 out of 16 Avoid group patients (25\%) who completed the intervention relapsed, as compared to 4 out of 19 control group patients $(21 \%)$. Of the patients who relapsed, relapse was significantly delayed in the ABM Avoid group compared to the control group, although it is important to note that this difference is based on an analysis of only eight participants (four from each group). Finally, among patients from one of the three study sites $(N=17)$, patients in the ABM Avoid group $(N=9)$ were discharged from treatment (based on their therapist's judgment of their recovery) sooner than patients in the control group $(N=8)$. This variable could not be tested in the other two study sites.

These results are encouraging: The study had an appropriate control condition (Boot, Simons, Stothart, \& Stutts, 2013) and the demonstration that multiple sessions of 
Christiansen, P., Schoenmakers, T.M., Field, M. Less than meets the eye: reappraising the

ABM Avoid training led to a reduction in $\mathrm{AB}$ that generalised to novel stimuli is an important finding. However, we contend that the relapse data should be treated with some scepticism, given that the findings that were reported were based on small subgroups of the overall sample that were tested.

McGeary, Meadows, Amir, and Gibb (2014) allocated 41 heavy drinking college students (who were not motivated to reduce their drinking) to Avoid or Control groups. Participants were instructed to complete a modified visual probe task containing personalised alcohol-related and control words twice per week for four weeks at home, and the frequency (but not quantity) of their alcohol consumption was measured immediately before and after training. Compliance in this study was good, with $73 \%$ of participants completing at least six ABM sessions over the four weeks. Most importantly, participants in the Avoid group reported a reduction in the frequency of drinking over the course of the study period, but participants in the Control group reported no change. Although this report lacks important information (such as descriptive statistics), we contacted the authors of the study and they confirmed that there were no group differences in drinking frequency before ABM. While these results are promising, our enthusiasm is limited by the failure to measure changes in attentional bias after ABM, the lack of a measure of quantity of alcohol consumption, and the general absence of methodological information (e.g. compliance rates in both groups). Nonetheless, this finding suggests that ABM may have some utility for heavy drinking college students, and it may be relevant that participants in this study completed ABM sessions in their own homes. We return to this point later.

Two trials of multi-session ABM for tobacco smokers were also reported in 2014. Lopes, Pires, and Bizarro (2014) administered ABM to a group of tobacco smokers who were enrolled in a one-month smoking cessation programme. Participants completed either 3 sessions of Avoid training ('Avoid 3'), 3 sessions of Control training ('Control'), or one session of Avoid training and two sessions of Control training ('Avoid 1') during the first two weeks of the smoking cessation programme. Results indicated a robust decrease in attentional bias in the 'Avoid 3' group compared to the other two groups, that did not differ from each other: this difference was evident at $24 \mathrm{~h}$ and one month after the last ABM session, but was not maintained at 6-month and one-year follow-up. However, there were no group differences in subjective craving or smoking behaviour.

More encouraging results were reported by Kerst and Waters (2014), who administered Avoid or Control ABM sessions via a personal digital assistant (PDA) to tobacco smokers who were not trying to quit. Participants completed on average $15 \mathrm{ABM}$ sessions over a one-week period in which they also reported their subjective craving (sometimes in response to smoking pictures) and their smoking behaviour. Over the course of the ABM period, both $\mathrm{AB}$ and 'cued' craving (in response to smoking pictures) decreased in the Avoid group compared to the Control group. There were no group differences in smoking behaviour but this is unsurprising given that participants in this study were not attempting to reduce or quit smoking at the time. This study is important because it demonstrates how ABM can be implemented on mobile devices (such as smartphones), and the results demonstrate that ABM delivered in this way results in a robust reduction in attentional bias and an associated reduction in subjective craving. It is important to extend this research by 
Christiansen, P., Schoenmakers, T.M., Field, M. Less than meets the eye: reappraising the

investigating the effects of ABM delivered in this way to groups of smokers who are attempting to quit smoking.

One much-cited study (Fadardi \& Cox, 2009) employed a modified Stroop task in order to train problem drinkers to overcome their attentional biases for alcoholrelated pictures. Participants were problem drinkers recruited from the local community who were drinking alcohol at unsafe levels and were divided into two groups based on their self-reported alcohol consumption: 'hazardous' drinkers (who consumed 22-50 UK units per week if male, 15-35 units per week if female, where one UK unit is equal to $8 \mathrm{~g}$ of alcohol) and 'harmful' drinkers (who consumed more than 50 units per week if male, more than 35 units per week if female). In their 'Alcohol Attention-Control Training Programme' participants completed a Stroop colour-naming task in which personalised alcohol-related pictures (e.g. of the participants' preferred brand of beer) were presented with a coloured border. Participants were required to name the colour in which the border was presented and the AACTP became progressively more difficult by reducing the size of the border, presenting more than one stimulus at a time, and requiring responses to be made more quickly than on previous blocks.

In this study, hazardous drinkers completed two training sessions one week apart, and alcohol consumption was not measured after training in this group. Harmful drinkers completed four training sessions with a one-week interval between sessions, and they reported their alcohol consumption immediately after the training and again at three-month follow-up. However, dropout rates were high in the harmful drinker group: only $60 \%$ of participants returned for the post-training assessments of $\mathrm{AB}$ and alcohol consumption. Results indicated that AACTP training was effective at reducing alcohol $\mathrm{AB}$ in both the hazardous and harmful drinkers. Most importantly, the harmful drinker group reported a reduction in alcohol-consumption immediately after the end of training, and this reduced level of drinking was maintained at threemonth follow-up.

The AACTP is an ingenious method for training participants to overcome their alcohol $\mathrm{AB}$, but the authors noted a number of limitations of their study design that seriously complicate interpretation of the findings. Most importantly, there was no control group. Therefore, as participants were completing the AACTP they believed that they were engaging in something that would help them to reduce their alcohol consumption and it is unsurprising that this is indeed what happened. The authors argued that participants did not report a reduction in alcohol consumption during the one-month 'waiting period' that occurred before they completed the AACTP, but this hardly constitutes the kind of active control condition that is required in evaluations of any psychological intervention (Boot et al., 2013). Indeed all other ABM intervention studies listed in Table 2 were able to include an appropriate active control condition.

In support of this interpretation, Wiers et al. (2015) investigated the efficacy of multiple sessions of the AACTP delivered via the internet to heavy drinkers. In this study, the AACTP was compared to an active control condition and to other forms of cognitive bias modification. Results indicated that all participants reported a reduction in alcohol consumption after training compared to the baseline period; there were no differences between the AACTP and control interventions (or the other forms of cognitive bias modification). The most parsimonious explanation for these findings is that participants reported a reduction in drinking simply because of non- 
Christiansen, P., Schoenmakers, T.M., Field, M. Less than meets the eye: reappraising the

specific effects of participating in a trial such as engagement with the intervention or monitoring of their alcohol consumption, and the results from the earlier AACTP trial can likely be attributed to these non-specific effects as well.

Taken together, we suggest that there is little reason to be enthusiastic about the clinical potential of multiple sessions of ABM when delivered in clinical or University settings, and this conclusion is supported by two recent meta-analyses which included many of the studies described here (Beard et al., 2012 and Mogoaşe et al., 2014). The results from the two studies with dependent and problem drinkers who were motivated to abstain or reduce their drinking ( Fadardi and Cox, 2009 and Schoenmakers et al., 2010) have been generously interpreted by many researchers, including ourselves, as evidence that ABM is likely to prove efficacious as an intervention for addictions. However given the enthusiasm about these studies, we are disappointed that replications with stronger research methods and larger sample sizes have not yet materialised. On balance, such enthusiastic reporting of these findings does not seem justified. Another interpretation of the existing research is that ABM may have a beneficial effect on drinking behaviour, but there is no evidence for an effect on smoking behaviour. Alternatively, the promising results from two recent studies that administered ABM sessions in participants' own homes or other naturalistic environments ( Kerst and Waters, 2014 and McGeary et al., 2014; but see Wiers et al., 2015), indicate that ABM may be effective if it is administered in environments in which participants have used substances in the past and will have the opportunity to consume them in the future (see Conklin \& Tiffany, 2002 , for related discussion), a point that we return to below.

\section{SYNTHESIS AND CONCLUDING COMMENTS}

We contend that there is no convincing evidence that $\mathrm{AB}$ measured in the clinic can predict relapse that occurs weeks or months later, and there is no convincing evidence that $\mathrm{ABM}$ administered in clinical or university settings can reduce the risk of relapse in the future. We have shown in this paper that many of the studies that claim to provide support for these claims are methodologically flawed and should be viewed in the context of the (far more numerous) negative findings.

However, AB may not be dead yet. Recently-published papers suggest that AB can predict imminent drug use (Marhe, Waters, Van De Wetering, \& Franken, 2013), and attentional bias modification administered in participants' home environments may promote robust reductions in bias, craving, and substance use (Kerst and Waters, 2014 and McGeary et al., 2014). In order to advance the field, we urge future researchers to make use of mobile technology to study the predictive validity of $A B$ and the behavioural effects of ABM, especially as a treatment intervention, and attempt to replicate these findings. We encourage further research on this topic, ideally using standardised measures of $\mathrm{AB}$ and substance use/relapse, because this will eventually yield enough data to permit a formal meta-analysis.

Our review of the evidence also has important theoretical implications. There is no convincing support for theoretical models which posit that $\mathrm{AB}$ is a stable characteristic within individuals that is predictive of, and has a causal influence on, their future substance use behaviour (Cox et al., 2006, Franken, 2003, Field and Cox, 2008 and Wiers et al., 2014). Therefore, these theoretical models may require revision to account for this. However, there is robust evidence that $\mathrm{AB}$ is correlated with the strength of subjective craving at that moment in time, albeit weakly (Field, 
Christiansen, P., Schoenmakers, T.M., Field, M. Less than meets the eye: reappraising the clinical relevance of attentional bias in addiction. Addictive Behaviors: 2015, 44(44-50), 44-50

Munafò, \& Franken, 2009), that it varies in line with the motivational value of the substance at that moment in time (Rose, Brown, Field, \& Hogarth, 2013), and that it is sensitive to environmental context and variables that influence the strength of subjective craving such as stress, acute alcohol effects, being in a cue-rich environment and the expectation of imminent substance availability (Field and Cox, 2008, Field, Munafò and Franken, 2009 and Jones et al., 2012). On the basis of these observations we argue that $\mathrm{AB}$ is an output of the current motivational state and that the strength of this motivational state is affected by the environmental and internal factors discussed above. Importantly, if $\mathrm{AB}$ varies in line with motivational state this need not imply that it plays a causal role in generating that motivational state. We suggest that the predictive validity of $\mathrm{AB}$ and clinical applications of $\mathrm{ABM}$ may also be sensitive to environmental context and proximity to substance use: $\mathrm{AB}$ may predict substance use in the short-term, and ABM may reduce the risk of substance use, but only if $\mathrm{AB}$ is measured, or $\mathrm{ABM}$ is administered, in settings in which substance use normally occurs. It may also be important to combine these observations and study the effects of ABM when it is administered only when subjective craving and accompanying $\mathrm{AB}$ are elevated - an exciting avenue for future research.

\section{Role of funding source}

Nothing declared.

\section{Contributors}

Christiansen conducted the literature search wrote the draft manuscript. Shoenmakers and Field contributed to all subsequent drafts and approved the final manuscript.

\section{Conflicts of interest}

No conflict declared.

\section{Acknowledgements}

None.

\section{REFERENCES}

Algom, D., Chajut, E., \& Lev, S. (2004). A rational look at the emotional stroop phenomenon: A generic slowdown, not a stroop effect. Journal of Experimental Psychology: General, 133, 323-338.

American Psychiatric Association (2013). Diagnostic and statistical manual of mental disorders (5th ed.). Arlington, VA: American Psychiatric Publishing.

Ataya, A.F., Adams, S., Mullings, E., Cooper, R.M., Attwood, A.S., \& Munafò,M.R. (2012). Internal reliability of measures of substance-related cognitive bias. Drug and Alcohol Dependence, 121(1-2), 148-151.

Attwood, A.S., O'Sullivan, H., Leonards, U., Mackintosh, B., \& Munafò, M.R. (2008). Attentional bias training and cue reactivity in cigarette smokers. Addiction, 103, 18751882.

Beard, C., Sawyer, A.T., \& Hofmann, S.G. (2012). Efficacy of attention bias modification using threat and appetitive stimuli: A meta-analytic review. Behavior Therapy, 43, 724-740.

Boot, W.R., Simons, D.J., Stothart, C., \& Stutts, C. (2013). The pervasive problem with placebos in psychology:Why active control groups are not sufficient to rule out placebo effects. Perspectives on Psychological Science, 8, 445-454.

Bowen, S., Witkiewitz, K., Clifasefi, S.L., Grow, J., Chawla, N., Hsu, S.H., et al. (2014). Relative efficacy of mindfulness-based relapse prevention, standard relapse prevention, and treatment as usual for substance use disorders. JAMA Psychiatry, 71, 547-556.

Button, K.S., Ioannidis, J.P.A.,Mokrysz, C., Nosek, B.A., Flint, J., Robinson, E.S.J., et al. (2013). 
Christiansen, P., Schoenmakers, T.M., Field, M. Less than meets the eye: reappraising the clinical relevance of attentional bias in addiction. Addictive Behaviors: 2015, 44(44-50), 44-50

Power failure: Why small sample size undermines the reliability of neuroscience.

[Analysis]. Nature Reviews Neuroscience, 14(5), 365-376. http://dx.doi.org/10.1038/ nrn3475.

Carpenter, K.M.,Martinez, D., Vadhan, N.P., Barnes-Holmes, D., \& Nunes, E.V. (2012). Measures of attentional bias and relational responding are associated with behavioral treatment outcome for cocaine dependence. American Journal of Drug and Alcohol Abuse, $38,146-154$.

Carpenter, K.M., Schreiber, E., Church, S., \& McDowell, D. (2006). Drug Stroop performance: Relationships with primary substance of use and treatment outcome in a drug-dependent outpatient sample. Addictive Behaviors, 31, 174-181.

Clarke, P.J.F., Notebaert, L., \& MacLeod, C. (2014). Absence of evidence or evidence of absence: Reflecting on therapeutic implementations of attentional bias modification.

BMC Psychiatry, 14.

Conklin, C.A., \& Tiffany, S.T. (2002). Applying extinction research and theory to cueexposure addiction treatments. Addiction, 97, 155-167.

Cox,W.M., Fadardi, J.S., Intriligator, J.M., \& Klinger, E. (2014). Attentional biasmodification for addictive behaviors: Clinical implications. CNS Spectrums, 19, 215-224.

Cox,W.M., Fadardi, J.S., \& Pothos, E.M. (2006). The Addiction-Stroop test: Theoretical considerations and procedural recommendations. Psychological Bulletin, 132(3), 443-476.

Cox, W.M., Hogan, L.M., Kristian, M.R., \& Race, J.H. (2002). Alcohol attentional bias as a predictor of alcohol abusers' treatment outcome. Drug and Alcohol Dependence, 68, 237243.

Cox,W.M., Pothos, E.M., \& Hosier, S.G. (2007). Cognitive-motivational predictors of excessive drinkers' success in changing. Psychopharmacology, 192, 499-510.

Crunelle, C.L., Veltman, D.J., Booij, J., van Emmerik - van Oortmerssen, K., \& van den Brink, W. (2012). Substrates of neuropsychological functioning in stimulant dependence: A review of functional neuroimaging research. Brain and Behavior, 2, 499-523.

De Ruiter, C., \& Brosschot, J.F. (1994). The emotional Stroop interference effect in anxiety:

Attentional bias or cognitive avoidance. Behaviour Research and Therapy, 32(3), 315-319.

Emmelkamp, P.M.G. (2012). Attention bias modification: The Emperor's new suit? BMC Medicine, 10.

Fadardi, J.S., \& Cox,W.M. (2009). Reversing the sequence: Reducing alcohol consumption by overcoming alcohol attentional bias. Drug and Alcohol Dependence, 101, 137-145.

Field, M., \& Cox,W.M. (2008). Attentional bias in addictive behaviors: A review of its development, causes, and consequences. Drug and Alcohol Dependence, 97, 1-20.

Field, M., \& Christiansen, P. (2012). Commentary on. Internal reliability of measures of substance-related cognitive bias, Drug and Alcohol Dependence, 124(3), 189-190.

Field, M., Duka, T., Eastwood, B., Child, R., Santarcangelo, M., \& Gayton, M. (2007). Experimental manipulation of attentional biases in heavy drinkers: Do the effects generalise? Psychopharmacology, 192, 593-608.

Field, M., Duka, T., Tyler, E., \& Schoenmakers, T. (2009). Attentional bias modification in tobacco smokers. Nicotine and Tobacco Research, 11, 812-822.

Field, M., \& Eastwood, B. (2005). Experimental manipulation of attentional bias increases the motivation to drink alcohol. Psychopharmacology, 183, 350-357.

Field, M., Marhe, R., \& Franken, I.H.A. (2014). The clinical relevance of attentional bias in substance use disorders. CNS Spectrums, 19, 225-230.

Field, M.,Mogg, K.,Mann, B., Bennett, G.A., \& Bradley, B.P. (2013). Attentional biases in abstinent alcoholics and their association with craving. Psychology of Addictive Behaviors, $27,71-80$.

Field, M., Munafò, M.R., \& Franken, I.H.A. (2009). A meta-analytic investigation of the relationship between attentional bias and subjective craving in substance abuse.

Psychological Bulletin, 135, 589-607.

Flaudias, V., Brousse, G., de Chazeron, I., Planche, F., Brun, J., \& Llorca, P.M. (2013). Treatment in hospital for alcohol-dependent patients decreases attentional bias.

Neuropsychiatric Disease and Treatment, 9, 773-779.

Franken, I.H.A. (2003). Drug craving and addiction: Integrating psychological and neuropsychopharmacological approaches. Progress in Neuro-Psychopharmacology and Biological Psychiatry, 27, 563-579. 
Christiansen, P., Schoenmakers, T.M., Field, M. Less than meets the eye: reappraising the clinical relevance of attentional bias in addiction. Addictive Behaviors: 2015, 44(44-50), 44-50

Gardini, S., Caffarra, P., \& Venneri, A. (2009). Decreased drug-cue-induced attentional bias in individuals with treated and untreated drug dependence. Acta Neuropsychiatrica, 21, 179-185.

Garland, E.L., Franken, I.H.A., \& Howard, M.O. (2012). Cue-elicited heart rate variability and attentional bias predict alcohol relapse following treatment. Psychopharmacology, 222, 1726.

Greenaway, R., Mogg, K., \& Bradley, B.P. (2012). Attentional bias for smoking-related information in pregnant women: Relationships with smoking experience, smoking attitudes and perceived harm to foetus. Addictive Behaviors, 37, 1025-1028.

Hill, A.B. (1965). The environment and disease: Association or causation? Proceedings of the Royal Society of Medicine, 58, 295-300.

Janes, A.C., Pizzagalli, D.A., Richardt, S., Frederick, B.D., Chuzi, S., Pachas, G., et al. (2010).

Brain reactivity to smoking cues prior to smoking cessation predicts ability to maintain tobacco abstinence. Biological Psychiatry, 67, 722-729.

Jones, A., Hogarth, L., Christiansen, P., Rose, A.K., Martinovic, J., \& Field, M. (2012).

Reward expectancy promotes generalized increases in attentional bias for rewarding stimuli.

Quarterly Journal of Experimental Psychology, 65, 2333-2342.

Kavanagh, D.J., Andrade, J., \& May, J. (2005). Imaginary relish and exquisite torture: The elaborated intrusion theory of desire. Psychological Review, 112, 446-467.

Kennedy, A.P., Gross, R.E., Ely, T., Drexler, K.P., \& Kilts, C.D. (2014). Clinical correlates of attentional bias to drug cues associated with cocaine dependence. American Journal on Addictions, 23, 478-484.

Kerst,W.F., \&Waters, A.J. (2014). Attentional retraining administered in the field reduces smokers' attentional bias and craving. Health Psychology, 33, 1232-1240.

Krause, M.R., Serlin, R.C., Ward, S.E., Rony, Y.Z., Ezenwa, M.O., \& Naab, F. (2010). Testing mediation in nursing research: Beyond Baron and Kenny. Nursing Research, 59, 288-294.

Lopes, F.M., Pires, A.V., \& Bizarro, L. (2014). Attentional bias modification in smokers trying to quit: A longitudinal study about the effects of number of sessions. Journal of Substance Abuse Treatment, 47, 50-57.

Marhe, R., Luijten, M., \& Franken, I.H.A. (2014). The clinical relevance of neurocognitive measures in addiction. Frontiers in Psychiatry, 4.

Marhe, R., Luijten,M., Van DeWetering, B.J.M., Smits,M., \& Franken, I.H.A. (2013). Individual differences in anterior cingulate activation associated with attentional bias predict cocaine use after treatment. Neuropsychopharmacology, 38, 1085-1093.

Marhe, R.,Waters, A.J., Van DeWetering, B.J.M., \& Franken, I.H.A. (2013). Implicit and explicit drug-related cognitions during detoxification treatment are associated with drug relapse: An ecological momentary assessment study. Journal of Consulting and Clinical Psychology, 81, 1-12.

Marissen, M.A.E., Franken, I.H.A., Waters, A.J., Blanken, P., Van Den Brink, W., \& Hendriks, V.M. (2006). Attentional bias predicts heroin relapse following treatment. Addiction, 101, $1306-1312$.

McGeary, J.E., Meadows, S.P., Amir, N., \& Gibb, B.E. (2014). Computer-delivered, homebased, attentional retraining reduces drinking behavior in heavy drinkers.

Psychology of Addictive Behaviors, 28, 559-562.

McHugh, R.K., Murray, H.W., Hearon, B.A., Calkins, A.W., \& Otto, M.W. (2010). Attentional bias and craving in smokers: The impact of a single attentional training session.

Nicotine and Tobacco Research, 12, 1261-1264.

Mitchell, M.R., Balodis, I.M., Devito, E.E., Lacadie, C.M., Yeston, J., Scheinost, D., et al. (2013). A preliminary investigation of Stroop-related intrinsic connectivity in cocaine dependence: Associationswith treatment outcomes. American Journal of Drug and Alcohol Abuse, 39, 392-402.

Mogoaşe, C., David, D., \& Koster, E.H.W. (2014). Clinical efficacy of attentional bias modification procedures: An updated meta-analysis. Journal of Clinical Psychology. http://dx.doi.org/10.1002/jclp.22081 (in press). 
Christiansen, P., Schoenmakers, T.M., Field, M. Less than meets the eye: reappraising the clinical relevance of attentional bias in addiction. Addictive Behaviors: 2015, 44(44-50), 44-50

Owen, A.M., Hampshire, A., Grahn, J.A., Stenton, R., Dajani, S., Burns, A.S., et al. (2010). Putting brain training to the test. Nature, 465, 775-778.

Powell, J., Dawkins, L.,West, R., \& Pickering, A. (2010). Relapse to smoking during unaided cessation: Clinical, cognitive and motivational predictors. Psychopharmacology, 212, 537549.

Rose, A.K., Brown, K., Field, M., \& Hogarth, L. (2013). The contributions of value-based decision-making and attentional bias to alcohol-seeking following devaluation.

Addiction, 108, 1241-1249.

Schoenmakers, T.M., de Bruin, M., Lux, I.F.M., Goertz, A.G., Van Kerkhof, D.H.A.T., \&Wiers, R.W. (2010). Clinical effectiveness of attentional bias modification training in abstinent alcoholic patients. Drug and Alcohol Dependence, 109, 30-36.

Schoenmakers, T., Wiers, R.W., Jones, B.T., Bruce, G., \& Jansen, A.T.M. (2007). Attentional re-training decreases attentional bias in heavy drinkers without generalization.

Addiction, 102, 399-405.

Spiegelhalder, K., Jähne, A., Kyle, S.D., Beil, M., Doll, C., Feige, B., et al. (2011). Is smokingrelated attentional bias a usefulmarker for treatment effects? Behavioral Medicine, 37, 26-34.

Streeter, C.C., Terhune, D.B., Whitfield, T.H., Gruber, S., Sarid-Segal, O., Silveri, M.M., et al. (2008). Performance on the Stroop predicts treatment compliance in cocainedependent individuals. Neuropsychopharmacology, 33, 827-836.

Waters, A.J., Shiffman, S., Bradley, B.P., \& Mogg, K. (2003). Attentional shifts to smoking cues in smokers. Addiction, 98, 1409-1417.

Waters, A.J., Shiffman, S., Sayette, M.A., Paty, J.A., Gwaltney, C.J., \& Balabanis, M.H. (2003).

Attentional bias predicts outcome in smoking cessation. Health Psychology, 22, 378-387.

Wiers, R.W., Field,M., \& Stacy, A.W. (2014). Passion's slave? In K. Sher (Ed.), Cognitive processes in alcohol and drug abuse. Oxford Handbook of Substance Use Disorders. Oxford: Oxford University Press.

Wiers, R.W., Houben, K., Fadardi, J.S., van Beek, P., Rhemtulla, M., \& Cox,W.M. (2015). Alcohol cognitive bias modification training for problem drinkers over the web.

Addictive Behaviors, 40(0), 21-26. http://dx.doi.org/10.1016/j.addbeh.2014.08.010. 
Christiansen, P., Schoenmakers, T.M., Field, M. Less than meets the eye: reappraising the clinical relevance of attentional bias in addiction. Addictive Behaviors: 2015, 44(44-50), 44-50

\section{TABLES}

Table 1

Summary of findings investigating the prospective association between $A B$ and relapse.

\begin{tabular}{|c|c|c|c|c|}
\hline Study & $\begin{array}{l}\text { Sample } \\
\text { ( } N \text {, excluding any } \\
\text { controls) }\end{array}$ & $\begin{array}{l}\text { AB assessment } \\
\text { method }\end{array}$ & AB outcome & Finding \\
\hline Cox et al. (2002) & $\begin{array}{l}\text { Alcohol } \\
\text { dependent (14) }\end{array}$ & Stroop & RT bias & $\begin{array}{l}\text { Stroop bias increased from pre- to } \\
\text { post-treatment in patients who subsequently } \\
\text { relapsed }\end{array}$ \\
\hline $\begin{array}{l}\text { Waters, Shiffman, Bradley, and Mogg (2003), Waters, } \\
\text { Shiffman, Sayette, et al. (2003)* }\end{array}$ & $\begin{array}{l}\text { Tobacco smokers } \\
(141)\end{array}$ & $\begin{array}{l}\text { Visual probe } \\
\text { Stroop }\end{array}$ & $\begin{array}{l}\text { RT bias } \\
\text { Acute Stroop RT bias } \\
\text { \& RT bias }\end{array}$ & $\begin{array}{l}\text { Greater Stroop bias associated with increased } \\
\text { relapse } \\
\text { (both measures, but significant only for acute } \\
\text { Stroop RT) } \\
\text { No association with visual probe bias }\end{array}$ \\
\hline Carpenter et al. (2006) & $\begin{array}{l}\text { Heroin dependent } \\
(10) \\
\text { Cannabis } \\
\text { dependent (25) } \\
\text { Cocaine } \\
\text { dependent (45) }\end{array}$ & Stroop & RT bias & $\begin{array}{l}\text { Greater cocaine Stroop bias associated with } \\
\text { increased cocaine relapse. } \\
\text { No predictive relationships in heroin } \\
\text { or cannabis groups }\end{array}$ \\
\hline Marissen et al. (2006) & $\begin{array}{l}\text { Heroin dependent } \\
(110)\end{array}$ & Stroop & $\begin{array}{l}\text { RT bias } \\
\text { Carry-over Stroop RT } \\
\text { bias }\end{array}$ & $\begin{array}{l}\text { Greater Stroop bias associated with increased } \\
\text { relapse (both measures) }\end{array}$ \\
\hline Cox et al. (2007) & $\begin{array}{l}\text { Heavy drinkers } \\
(158)\end{array}$ & Stroop & RT bias & $\begin{array}{l}\text { Greater Stroop bias associated with a greater } \\
\text { number of drinking days }\end{array}$ \\
\hline Janes et al. (2010) & $\begin{array}{l}\text { Tobacco smokers } \\
\text { (19) }\end{array}$ & Stroop & $\begin{array}{l}\text { Acute Stroop RT bias } \\
\text { Acute Stroop errors } \\
\text { bias } \\
\text { Stroop RT bias } \\
\text { Stroop errors bias }\end{array}$ & $\begin{array}{l}\text { Greater acute Stroop bias associated with } \\
\text { relapse (RT and errors) } \\
\text { Stroop RT bias but not Stroop errors bias also } \\
\text { associated with relapse }\end{array}$ \\
\hline Powell et al. (2010) & $\begin{array}{l}\text { Tobacco smokers } \\
\text { (141) }\end{array}$ & Stroop & Stroop errors bias & $\begin{array}{l}\text { Greater Stroop errors bias associated } \\
\text { with increased relapse }\end{array}$ \\
\hline Spiegelhalder et al. (2011) & $\begin{array}{l}\text { Tobacco smokers } \\
\text { (59) }\end{array}$ & $\begin{array}{l}\text { Stroop } \\
\text { Visual probe }\end{array}$ & RT bias & $\begin{array}{l}\text { Greater Stroop bias associated with reduced } \\
\text { relapse } \\
\text { No association with visual probe bias }\end{array}$ \\
\hline Carpenter et al. (2012) & $\begin{array}{l}\text { Cocaine } \\
\text { dependent (25) }\end{array}$ & Stroop & RT bias & $\begin{array}{l}\text { Greater Stroop bias associated with reduced } \\
\text { relapse }\end{array}$ \\
\hline Garland et al. (2012) & $\begin{array}{l}\text { Alcohol } \\
\text { dependent (53) }\end{array}$ & Visual probe & RT bias & Greater bias associated with increased relapse \\
\hline Field et al. (2013) & $\begin{array}{l}\text { Alcohol } \\
\text { dependent (28) }\end{array}$ & $\begin{array}{l}\text { Stroop } \\
\text { Visual probe }\end{array}$ & RT bias & No associations \\
\hline Marhe, Luijten et al. (2013) & $\begin{array}{l}\text { Cocaine } \\
\text { dependent (26) }\end{array}$ & Stroop & $\begin{array}{l}\text { RT bias } \\
\text { Stroop errors bias }\end{array}$ & No association \\
\hline Marhe, Waters et al. (2013) & $\begin{array}{l}\text { Heroin dependent } \\
(68)\end{array}$ & Stroop (EMA) & RT bias & $\begin{array}{l}\text { Greater Stroop bias during temptation } \\
\text { episodes predicted relapse }\end{array}$ \\
\hline Mitchell et al. (2013) & $\begin{array}{l}\text { Cocaine } \\
\text { dependent (15) }\end{array}$ & Stroop & RT bias & $\begin{array}{l}\text { Greater Stroop bias associated with } \\
\text { reduced relapse }\end{array}$ \\
\hline Kennedy et al. (2014) & $\begin{array}{l}\text { Cocaine } \\
\text { dependent (35) }\end{array}$ & Stroop & $\begin{array}{l}\text { RT bias } \\
\text { Stroop errors bias }\end{array}$ & No association \\
\hline
\end{tabular}

RT = reaction time; acuteStroop: first few trials of task only; carry over Stroop = Mean reaction times on trials that follow substance related words minus mean reaction times from trials following neutral words.

* Data for the two papers are derived from the same study. 
Christiansen, P., Schoenmakers, T.M., Field, M. Less than meets the eye: reappraising the clinical relevance of attentional bias in addiction. Addictive Behaviors: 2015, 44(44-50), 44-50

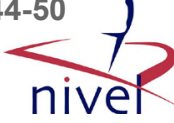

Table 2

Summary of findings from published ABM studies.

\begin{tabular}{|c|c|c|c|c|c|}
\hline Study & Sample $(N)$ & ABM method & Conditions & $\begin{array}{l}\text { Did } A B M \\
\text { change } \\
A B \text { ? }\end{array}$ & Self-report and behavioural outcomes \\
\hline $\begin{array}{l}\text { Field and } \\
\text { Eastwood } \\
(2005)\end{array}$ & $\begin{array}{l}\text { Heavy drinkers } \\
(40)\end{array}$ & $\begin{array}{l}\text { Visual probe, } \\
1 \text { session }\end{array}$ & $\begin{array}{l}\text { Attend }(N=20) \\
\text { Avoid }(N=20)\end{array}$ & Yes & $\begin{array}{l}\text { Increased urge and beer consumption in Attend } \\
\text { vs. Avoid; no difference in craving }\end{array}$ \\
\hline $\begin{array}{l}\text { Field et al. } \\
\text { (2007) }\end{array}$ & $\begin{array}{l}\text { Heavy drinkers } \\
(60)\end{array}$ & $\begin{array}{l}\text { Visual probe, } \\
1 \text { session }\end{array}$ & $\begin{array}{l}\text { Attend }(N=20) \\
\text { Avoid }(N=20) \\
\text { Control }(N=20)\end{array}$ & Yes & $\begin{array}{l}\text { No group differences in urge, craving, or } \\
\text { drinking behaviour }\end{array}$ \\
\hline $\begin{array}{l}\text { Schoenmakers } \\
\text { et al. (2007) }\end{array}$ & $\begin{array}{l}\text { Heavy drinkers } \\
(106)\end{array}$ & $\begin{array}{l}\text { Visual probe, } \\
1 \text { session }\end{array}$ & $\begin{array}{l}\text { Avoid }(N=53) \\
\text { Control }(N=53)\end{array}$ & Yes & $\begin{array}{l}\text { No group differences in craving or alcohol } \\
\text { preference }\end{array}$ \\
\hline $\begin{array}{l}\text { Attwood et al. } \\
\text { (2008) }\end{array}$ & $\begin{array}{l}\text { Tobacco } \\
\text { smokers (54) }\end{array}$ & $\begin{array}{l}\text { Visual probe, } \\
1 \text { session }\end{array}$ & $\begin{array}{l}\text { Attend }(N=27) \\
\text { Avoid }(N=27)\end{array}$ & Yes & $\begin{array}{l}\text { Increased urge in Attend group (Males only). No } \\
\text { difference in smoking behaviour }\end{array}$ \\
\hline $\begin{array}{l}\text { Field, Duka, } \\
\text { et al. (2009) }\end{array}$ & $\begin{array}{l}\text { Tobacco } \\
\text { smokers }(72)\end{array}$ & $\begin{array}{l}\text { Visual probe, } \\
1 \text { session }\end{array}$ & $\begin{array}{l}\text { Attend }(N=24) \\
\text { Avoid }(N=24) \\
\text { Control }(N=24)\end{array}$ & Yes & $\begin{array}{l}\text { No group differences in urge to smoke, craving, } \\
\text { or smoking behaviour }\end{array}$ \\
\hline $\begin{array}{l}\text { Fadardi and } \\
\text { Cox (2009) }\end{array}$ & $\begin{array}{l}\text { Tobacco } \\
\text { smokers (51) }\end{array}$ & $\begin{array}{l}\text { Visual probe, } \\
1 \text { session }\end{array}$ & $\begin{array}{l}\text { Avoid }(N=26) \\
\text { Control }(N=25)\end{array}$ & No & $\begin{array}{l}\text { No group differences in craving } \\
\text { Behaviour not measured }\end{array}$ \\
\hline $\begin{array}{l}\text { McHugh et al. } \\
(2010)\end{array}$ & $\begin{array}{l}\text { Heavy drinkers } \\
(160)\end{array}$ & $\begin{array}{l}\text { Stroop, } 2 \text { sessions for 'hazardous' } \\
\text { drinkers, } 5 \text { sessions for 'harmful' } \\
\text { drinkers }\end{array}$ & $\begin{array}{l}\text { Avoid }(N=160) \text {, for 'hazardous' } \\
\text { drinkers }(N=68) \text { and 'harmful' } \\
(N=92) \text { drinkers }\end{array}$ & Yes & $\begin{array}{l}\text { Reduced alcohol consumption in 'harmful' } \\
\text { drinkers ( not reported in 'hazardous' drinkers) }\end{array}$ \\
\hline $\begin{array}{l}\text { Schoenmakers } \\
\text { et al. (2010) }\end{array}$ & $\begin{array}{l}\text { Alcohol- } \\
\text { dependent } \\
\text { patients (43) }\end{array}$ & Visual probe. 5 sessions & $\begin{array}{l}\text { Avoid }(N=21) \\
\text { Control }(N=22)\end{array}$ & Yes & $\begin{array}{l}\text { Relapse rates: } N=4 \text { in both groups. See text } \\
\text { for other outcome measures }\end{array}$ \\
\hline $\begin{array}{l}\text { Kerst and } \\
\text { Waters } \\
(2014)\end{array}$ & $\begin{array}{l}\text { Tobacco } \\
\text { smokers }(60)\end{array}$ & Visual probe, mean of 15 sessions & $\begin{array}{l}\text { Avoid }(N=30) \\
\text { Control }(N=30)\end{array}$ & Yes & $\begin{array}{l}\text { Reduced cue-provoked craving in Avoid } \\
\text { compared to Control group, no effect on } \\
\text { smoking behaviour }\end{array}$ \\
\hline $\begin{array}{l}\text { Lopes et al. } \\
\text { (2014) }\end{array}$ & $\begin{array}{l}\text { Tobacco } \\
\text { smokers (67) }\end{array}$ & Visual probe, 3 sessions & $\begin{array}{l}3 \text { sessions Avoid }(N=22) \\
1 \text { session Avoid }+2 \text { sessions control } \\
(N=22) \\
3 \text { sessions Control }(N=23)\end{array}$ & Yes & No effect on craving or smoking behaviour \\
\hline $\begin{array}{l}\text { McGeary et al. } \\
\text { (2014) } \\
\text { Wiers et al. } \\
\text { (2015) }\end{array}$ & $\begin{array}{l}\text { Heavy drinkers } \\
(41) \\
\text { Heavy drinkers } \\
(136)\end{array}$ & $\begin{array}{l}\text { Visual probe, up to } 8 \text { sessions } \\
\text { Stroop, four sessions }\end{array}$ & $\begin{array}{l}\text { Avoid }(N=22) \\
\text { Control }(N=19) \\
\text { Avoid }(N=17) \\
\text { Control }(N=24) \\
\text { Other CBM }(N=95)\end{array}$ & $\begin{array}{l}\text { Not } \\
\text { measured } \\
\text { Not } \\
\text { measured }\end{array}$ & $\begin{array}{l}\text { Reduced frequency of drinking in Avoid group, } \\
\text { craving not measured } \\
\text { All participants reduced drinking, no } \\
\text { differences between groups }\end{array}$ \\
\hline
\end{tabular}

